\title{
The Somatostatin Analogue Octreotide Impairs Sleep and Decreases EEG Sigma Power in Young Male Subjects
}

\author{
M Ziegenbein', K Held', HE Kuenzel', H Murck', IA Antonijevic' and A Steiger*,' \\ 'Department of Psychiatry, Max-Planck-Institute of Psychiatry, Munich, Germany
}

\begin{abstract}
The long-acting somatostatin (SRIF) analogue octreotide decreased nonrapid eye movement sleep (NREMS) in the rat. This effect is opposite to the promotion of sleep after growth hormone $(\mathrm{GH})$-releasing hormone $(\mathrm{GHRH})$ in various species including humans. Therefore, it appears likely that GHRH and SRIF, besides their opposite action on pituitary GH release, interact reciprocally in sleep regulation. In previous studies, SRIF impaired sleep in elderly subjects, although sleep in young men remained unchanged. We hypothesized that octreotide is a useful tool to study the role of SRIF in human sleep regulation. We examined the effect of subcutaneous administration of $0.1 \mathrm{mg}$ octreotide at 2245 on the sleep EEG of seven young male controls (age, mean \pm SD, $22.3 \pm 3.0$ years). In comparison to placebo, octreotide administration prompted decreases of sleep stage 4 during the total night and of rapid eye movement sleep (REMS) density during the first half of the night. Intermittent wakefulness increased during the second half of the night. The spectral analysis of total night NREMS revealed a significant decrease of sigma power. Similar to the effect of the short-acting SRIF in the elderly, the long-acting SRIF analogue octreotide impaired sleep in young healthy subjects. Obviously, the influence of octreotide on sleep is superior to that of short-acting SRIF, which did not affect sleep in young men. We suggest a reciprocal interaction of GHRH and SRIF in sleep regulation.

Neuropsychopharmacology (2004) 29, I46-I5I, advance online publication, 03 September 2003; doi: I 0. I 038/sj.npp. I 300298
\end{abstract}

Keywords: octreotide; somatostatin; sleep; peptides; GHRH

\section{INTRODUCTION}

The hormones of the somatotrophic system play a key role in sleep regulation in various species, including humans (As reviewed in: Obál and Krueger, 2001; Steiger, 2002). Particularly, the major endogenous stimulus of growth hormone $(\mathrm{GH})$-releasing hormone $(\mathrm{GHRH})$ is known to be an important sleep-promoting factor. Recently, ghrelin was identified as another endogenous GH secretagogue (Kojima et al, 1999). Interestingly, ghrelin shares the sleep-promoting effect of GHRH in humans (Weikel et al, 2003) and mice (Obál et al, 2003). The endogenous antagonist of GHRH in the pituitary release of GH is somatostatin (SRIF). The role of SRIF in sleep regulation is less clear, particularly in humans. The long-acting SRIF analogue octreotide appears to be a useful tool to investigate the effects of SRIF in human sleep. Here, we report the influence of octreotide on sleep EEG in young normal human subjects.

*Correspondence: Dr A Steiger, Department of Psychiatry, MaxPlanck-Institute of Psychiatry, Kraepelinstr. 2-10, 80804 Munich, Germany, Tel: + 49 30622236, Fax: + 4930622552 ,

E-mail: steiger@mpipsykl.mpg.de

Received 03 December 2002; revised 28 July 2003; accepted 29 July 2003

Online publication: 30 July 2003 at http://www.acnp.org/citations/ Npp07300302440/default.pdf
Preclinical studies showed increases of nonrapid eye movement sleep (NREMS) when GHRH was injected intraventricularly (i.c.v.) into rabbits (Obál et al, 1988) and rats (Obál et al, 1988; Ehlers et al, 1986; Nistico et al, 1987), intravenously (i.v.) into rats (Obál et al, 1996), intraperitoneally (i.p.) into mice (Obál and Krueger, 2001) and into the area preoptica in rats (Zhang et al, 1999). Similarly, SWS increased after i.v. GHRH in young normal male subjects (Steiger et al, 1992; Kerkhofs et al, 1993; Marshall et al, 1996) and NREMS increased in a large group of healthy and depressed male subjects of a wide age range, whereas sleep was impaired after i.v. GHRH in female subjects (Antonijevic et al, 2000a, b). Also, in healthy elderly women and men a sleep-promoting effect of i.v. GHRH was found, whereas it was weaker than that in young men (Guldner et al, 1997). In various animal models of reduced GHRH activity NREMS is decreased, as after the suppression of endogenous GHRH by GHRH antibodies (Obál et al, 1991), GHRH antagonists (Obál et al, 1992), in mutant dwarf rats (Obál et al, 2001), in dwarf mice with GHRH receptor deficiencies (Obál et al, 2003), and in transgenic mice with decreased GHRH production (Zhang et al, 1996). The diurnal variation of GHRH mRNA levels (Bredow et al, 1996) and GHRH contents (Gardi et al, 1999) in the rat hypothalamus suggests distinct synthesis and release of GHRH, when the peak of NREMS occurs during the first portion of the rest period. 
Already, an early study reported a decrease of NREMS after SRIF in the rat (Rezek et al, 1976). A series of experiments by Danguir and co-workers (Danguir, 1986, 1989; Danguir and De Saint-Hilaire-Kafi, 1989) showed that SRIF enhances rapid eye movement sleep (REMS) in the rat. A comment to these papers mentioned that NREMS is often not reported or that the time blocks presented are too long to detect an immediate and short-lasting inhibition of NREMS (Obál and Krueger, 2002). We and others failed to show significant effects of SRIF on sleep in young normal subjects. Neither continuous (Parker et al, 1974; Kupfer et al, 1992) nor repetitive i.v. administration of SRIF (Steiger et al, 1992) modulated sleep EEG in healthy adults $20-40$ years old. However, when the latter protocol was applied in a sample of elderly normal women and men, sleep was impaired (Frieboes et al, 1997). In this study, after SRIF administration, the total sleep time and REMS decreased and more time was spent awake in the first sleep cycle. We discussed that SRIF may become more effective in sleep EEG in older than in younger subjects because of the decline of GHRH-GH axis activity.

In contrast to SRIF, which is eliminated in a few minutes, its synthetic octopeptide analogue octreotide is more resistant to hydrolysis, and has a half-life of $45-100 \mathrm{~min}$. Octreotide binds to human SRIF-2 and SRIF-5 receptors and weakly to SRIF-3 receptors (Reisine, 1995). Its potency to suppress GH is 20- to 75 -fold in comparison to endogenous SRIF. After subcutaneous (s.c.) and after i.c.v. administration of octreotide, NREMS was suppressed dose dependently in rats (Beranek et al, 1997, 1999). This effect was followed by distinct increases of EEG slow-wave activity during NREMS 2-3 h after administration.

We hypothesized that due to its longer half-life, octreotide is superior to SRIF in modulating human sleep. Therefore, we compared the effects of octreotide and placebo on the sleep EEG in young normal male subjects.

\section{METHODS}

The study group consisted of seven paid healthy young male volunteers of normal weight and height (age mean $\pm \mathrm{SD}, 22.3 \pm 3.0$ years; range, $18-24$ years). Before entering the study, they underwent extensive physical, psychiatric, and laboratory examinations. Individuals with a personal or family history of psychiatric disorder or a recent stressful life event were excluded from the study. Laboratory tests included hematology, virology, clinical chemistry, endocrinology, EEG, and electrocardiography. Subjects who had made a transmeridian flight during the last 3 months were not admitted to the study. Sleep disorders such as sleep apnea, restless legs syndrome, or periodic movement syndrome were excluded by a two-night screening registration in the sleep laboratory. Abuse of drugs, heavy alcohol, and any history of use of medication during the last 3 months were also reasons for exclusion. Written informed consent was received from all the subjects before they entered the study. The study was approved by the Ethics Committee for human experiments of the Bayerische Landesärztekammer (Bavarian Physicians' Board).

\section{STUDY PROTOCOL}

The subjects had two sessions in the sleep laboratory at 1week intervals consisting of one adaptation and one examination night. Octreotide measuring $0.1 \mathrm{mg}$ (Sandostatin ${ }^{\circledR}$, Novartis Pharma, Basel, Switzerland) or placebo (saline) was injected s.c. at 2245 according to a randomized double-blind schedule. This dose corresponds to the initial dose in the clinical use of the substance. Patients with acromegaly receive, according to $\mathrm{GH}$ and insulin-likegrowth-factor I levels, $0.3-1.5 \mathrm{mg}$ octreotide s.c. per day. For the treatment of hormone producing gastrointestinal tumors, $0.05-0.6 \mathrm{mg}$ s.c. octreotide is given daily.

Polygraphic recordings (EEG, electro-oculogram, electromyogram) were monitored between 2300 and 0700 . The subjects were not allowed to sleep before 'lights off at 2300 and they were awakened at 0700 . Outside of the period of polygraphic recordings, naps were not allowed. Sleep-EEG recordings were scored manually by a rater who was unaware of the treatment and experienced in the use of standard guidelines, as previously described (Rechtschaffen and Kales, 1968; Holsboer et al, 1988).

In addition, EEG spectral analysis was performed for all epochs containing stages 2, 3, or 4 of NREMS (Murck et al, 1996). By means of a personal computer, EEG signals were additionally sampled by an 8-bit analog-to-digital converter at a sampling rate of $100 \mathrm{~Hz}$ and stored on a disk for further spectral analysis. Subsequently, the 8-h EEG recordings (C3A2 derivation) were submitted to Fast Hartley Transformation (Bracewell, 1986; Trachsel et al, 1992) using 2.56-s intervals, which results in a frequency resolution of $0.39 \mathrm{~Hz}$. EEG power spectra were computed for consecutive rectangular windows of 256 samples. Frequency bins above $\approx 20 \mathrm{~Hz}$ were omitted from further analysis. EEG spectra were aligned with 30-s epochs of the visual scores by averaging the EEG spectra over 12 consecutive windows. The routine stepped back 72 samples before analyzing the following 12 windows. EEG power was averaged across the distinct frequency ranges delta $(0.5-4.5 \mathrm{~Hz})$, theta $(4.5-$ $8.0 \mathrm{~Hz})$, alpha $(8.0-11.8 \mathrm{~Hz})$, sigma $(11.8-15.2 \mathrm{~Hz})$, and beta $(15.2-20.0 \mathrm{~Hz})$ and thereafter using the single frequency bins. The mean values of EEG spectral power per frequency bin in each sleep cycle were computed for combined nonREM sleep stages 2-4.

After awakening, the subjects were asked about their subjective sleep quality.

\section{STATISTICS}

For all of the sleep variables investigated, the group values were expressed as mean \pm standard deviation (SD). The mean differences between the placebo and the octreotide groups were tested for significance with the paired Wilcoxon rank test. An alpha value of 0.05 was accepted as the nominal level of significance. Normally, the differences had to be tested at a reduced level of significance to keep the type I error less than or equal to the nominal level. However, the small sample size and the choice of the nonparametric Wilcoxon's rank test make testing of null hypotheses against the alternative hypotheses very conservative. Supplementary reduction of the nominal level by applying, for example, the Bonferroni correction would 
make the testing extremely conservative and that would consequently lead almost surely to nonrejection of all null hypotheses, even in cases where the group means differ strongly from each other.

\section{RESULTS}

\section{Conventional Sleep-EEG Analysis}

Table 1 shows the conventional sleep-EEG analysis after s.c. administration of octreotide and placebo. At baseline

Table I Sleep EEG Variables after Placebo and Octreotide Administration

\begin{tabular}{lccc}
\hline & $\begin{array}{c}\text { Placebo } \\
\text { (mean } \pm \text { SD) }\end{array}$ & $\begin{array}{c}\text { Octreotide } \\
\text { (mean } \pm \text { SD) }\end{array}$ & WRT I : 2 \\
\hline Sleep continuity & & & \\
SPT (min) & $461.5 \pm 11.1$ & $458.2 \pm 6.1$ & NS \\
TST (min) & $457.6 \pm 9.6$ & $437.3 \pm 32.6$ & NS \\
SEI & $0.96 \pm 0.02$ & $0.9 \pm 0.07$ & NS \\
Sleep latency & $14.6 \pm 8.2$ & $18.9 \pm 6.8$ & NS \\
(min) & $7.5 \pm 6.4$ & $10.5 \pm 7.7$ & NS \\
Awakenings & & &
\end{tabular}

Sleep architecture, min spent in each stage during the total night

$\begin{array}{lccc}\text { Awake } & 20.0 \pm 9.4 & 22.7 \pm 29.8 & \text { NS } \\ \text { Stage I } & 35.9 \pm 26.1 & 33.0 \pm 13.6 & \text { NS } \\ \text { Stage 2 } & 240.8 \pm 26.1 & 240.1 \pm 31.0 & \text { NS } \\ \text { Stage 3 } & 33.7 \pm 17.3 & 33.7 \pm 15.3 & \text { NS } \\ \text { Stage 4 } & 50.8 \pm 31.0 & 40.8 \pm 27.4 & p<0.05 \\ \text { SWS } & 84.4 \pm 35.8 & 74.4 \pm 27.1 & \text { NS } \\ \text { REMS } & 90.0 \pm 23.0 & 84.1 \pm 25.3 & \text { NS } \\ \text { REMS density } & 0.38 \pm 0.1 & 0.36 \pm 0.1 & \text { NS }\end{array}$

Sleep architecture, min spent in each stage during the first half of the night

$\begin{array}{lccc}\text { Awake } & 13.3 \pm 7.2 & 17.3 \pm 6.9 & \text { NS } \\ \text { Stage 1 } & 12.9 \pm 11.8 & 12.8 \pm 10.6 & \text { NS } \\ \text { Stage 2 } & 115.0 \pm 16.5 & 113.3 \pm 19.8 & \text { NS } \\ \text { Stage 3 } & 20.3 \pm 14.2 & 24.3 \pm 11.5 & \text { NS } \\ \text { Stage 4 } & 44.5 \pm 29.8 & 35.7 \pm 21.5 & \text { NS } \\ \text { SWS } & 64.8 \pm 30.0 & 59.9 \pm 19.3 & \text { NS } \\ \text { REMS } & 30.1 \pm 19.1 & 32.3 \pm 15.1 & \text { NS } \\ \text { REMS density } & 0.32 \pm 0.1 & 0.23 \pm 0.1 & \end{array}$

Sleep architecture, min spent in each stage during the second half of the night

$\begin{array}{lccc}\text { Awake } & 6.7 \pm 7.3 & 21.3 \pm 30.0 & p<0.05 \\ \text { Stage 1 } & 23.0 \pm 15.4 & 20.2 \pm 8.1 & \text { NS } \\ \text { Stage 2 } & 125.8 \pm 17.3 & 126.3 \pm 34.5 & \text { NS } \\ \text { Stage 3 } & 13.3 \pm 7.8 & 9.4 \pm 9.9 & \text { NS } \\ \text { Stage 4 } & 6.3 \pm 11.0 & 5.8 \pm 9.3 & \text { NS } \\ \text { SWS } & 19.6 \pm 14.8 & 14.5 \pm 14.6 & \text { NS } \\ \text { REMS } & 59.9 \pm 16.8 & 51.8 \pm 12.0 & \text { NS } \\ \text { REMS density } & 0.40 \pm 0.2 & 0.43 \pm 0.2 & \text { NS }\end{array}$

SPT, sleep period time; TST, total sleep time; SEl, sleep efficiency index; SWS, slow-wave sleep (stages 3 and 4); REMS, rapid eye movement sleep; WRT, Wilcoxon's rank test; NS, not significant. All results are given as mean \pm SD. conditions, sleep-EEG variables were as expected in a sample of normal young controls (Williams et al, 1974; Lauer et al, 1991). After octreotide, sleep stage 4 during the total night and REM density during the first half of the night decreased significantly. Intermittent wakefulness increased during the second half of the night after octreotide.

\section{EEG Spectral Analysis}

In the spectral analysis of NREMS, there was a significant decrease of EEG activity in the sigma frequency range (Table 2, Figure 1). No further significant effect of the substance on sleep-EEG variables was observed. There was a nonsignificant trend of EEG delta power to decrease during the first half of the night. Conversely, delta power increased by trend during the second half of the night.

\section{Subjective Sleep Quality}

The subjects did not report differences in subjective sleep quality between octreotide and placebo nights.

\section{DISCUSSION}

Our data show decreases of stage 4 sleep and EEG sigma activity during the total night, and of REM density during the first half of the night and increased wakefulness during the second half of the night after s.c. octreotide in normal young male subjects. Our findings support the hypothesis that octreotide is more useful than SRIF itself to delineate

Table 2 Effects of Octreotide on Mean Spectral Power $\left(\mu \bigvee^{2}\right)$ for non-REM Sleep

\begin{tabular}{|c|c|c|c|}
\hline & $\begin{array}{c}\text { Placebo } \\
(\text { mean } \pm \text { SD })\end{array}$ & $\begin{array}{c}\text { Octreotide } \\
(\text { mean } \pm \text { SD })\end{array}$ & WRT I : 2 \\
\hline \multicolumn{4}{|c|}{ Total night } \\
\hline Delta & $379.1 \pm 194.7$ & $363.5 \pm 179.3$ & NS \\
\hline Theta & $28.7 \pm 13.0$ & $28.6 \pm 12.6$ & NS \\
\hline Alpha & $19.0 \pm 8.1$ & $17.4 \pm 7.1$ & NS \\
\hline Sigma & $16.4 \pm 7.0$ & $14.8 \pm 5.9$ & $p<0.05$ \\
\hline Beta & $4.3 \pm 1.0$ & $3.7 \pm 1.4$ & NS \\
\hline \multicolumn{4}{|c|}{ First half of the night } \\
\hline Delta & $484.1 \pm 262.5$ & $452.8 \pm 214.5$ & NS \\
\hline Theta & $33.1 \pm 16.3$ & $32.0 \pm 14.2$ & NS \\
\hline Alpha & $21.6 \pm 10.5$ & $18.5 \pm 8.4$ & NS \\
\hline Sigma & $16.5 \pm 7.6$ & $14.1 \pm 6.2$ & $p<0.05$ \\
\hline Beta & $4.4 \pm 1.8$ & $3.7 \pm 1.6$ & NS \\
\hline \multicolumn{4}{|c|}{ Second half of the night } \\
\hline Delta & $245.9 \pm|4| . \mid$ & $253.0 \pm 155.6$ & NS \\
\hline Theta & $23.4 \pm 10.0$ & $24.3 \pm 10.7$ & NS \\
\hline Alpha & $16.0 \pm 6.3$ & $16.0 \pm 5.6$ & NS \\
\hline Sigma & $16.4 \pm 6.3$ & $15.7 \pm 5.8$ & NS \\
\hline Beta & $4.2 \pm 1.3$ & $3.8 \pm 1.2$ & NS \\
\hline
\end{tabular}




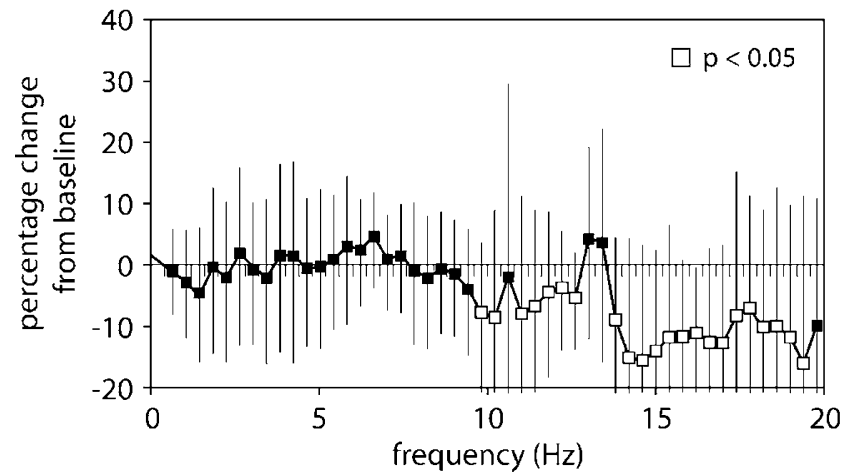

Figure I Changes of EEG power in NREMS after subcutaneous injection of $0.1 \mathrm{mg}$ octreotide in comparison to placebo in young normal male controls $(n=7)$. Open squares indicate significant differences; black squares indicate no significance. Bars indicate standard errors of the mean.

the effects of sleep-EEG in young normal subjects. Our data suggest that SRIF, probably acting as an antagonist to GHRH, impairs sleep in humans.

Since SWS decreased after octreotide, one may have also expected a decrease of EEG delta power. Whereas no significant change of this variable occurred, the delta power decreased by trend during the first half of the night. This tendency was reversed during the second half of the night. The low sample size and relatively high interindividual variations may explain that delta power does not change significantly. Interestingly, EEG power decreased significantly in the sigma range. Sigma power is enhanced after benzodiazepines (Lancel and Steiger, 1999), whereas the steroid pregnenolone, which is thought to be an inverse agonist at the $\mathrm{GABA}_{\mathrm{A}}$ receptor, prompted a decrease of sigma power in humans (Steiger et al, 1993). After s.c. administration, octreotide probably interacts with peripheral SRIF receptors. At the periphery, SRIF inhibits various functions, for example, secretion of gastric acid, gastrointestinal hormones, and insulin. Furthermore, octreotide may interact with SRIF receptors in sensory neurons.

Nevertheless, it appears likely that the changes of sleepEEG after octreotide reflect the action in the CNS. It was suggested that GABAergic neurons mediate the sleeppromoting activity of hypothalamic GHRHergic neurons (Obál and Krueger, 2002). Therefore, also the decrease of EEG sigma power points to an antagonistic action of octreotide on GHRH as the mechanism of its influence on sleep-EEG. This view is supported by preclinical data. It was shown that the suppression of NREMS after octreotide is independent from its angiotensin-like effects (Beranek et al, 1997). After octreotide, GHRH release was inhibited followed by an accumulation of GHRH (Gardi et al, 2001). Sleep was suppressed after microinjection of octreotide into the arcuate nucleus, anterior hypothalamus, and medial preoptic region. These sites correspond to the location of the GHRHergic cell bodies and terminals (Obál and Krueger, 2002). The sleep response to octreotide was attenuated in transgenic mice with decreased GHRH production (Hajdu et al, 2002) and was abolished in mice with deficient GHRH receptors (Obál et al, 2003).

In the present study, REMS density decreased after octreotide during the first half of the night. Similarly, REMS decreased after SRIF in elderly subjects (Frieboes et al, 1997). These findings suggest that SRIF inhibits REMS in humans, either by decreasing the amount of rapid eye movements in young subjects or by decreasing the time spent in REMS in the elderly. This observation points again to a GHRH antagonistic action of SRIF, since GHRH increased, besides NREMS and also REMS, in some (Kerkhofs et al, 1993; Marshall et al, 1996) but not all studies (Steiger et al, 1992) in humans and in rats (Obál and Krueger, 2001). In contrast, Danguir and co-workers reported increases of REMS after i.c.v. SRIF (Danguir, 1986) and after systemic administration of an SRIF analogue (SMS 201-995) in aged rats (Danguir, 1989), the suppression of REMS after scopalomine (Danguir and De Saint-HilaireKafi, 1988), or after desipramine (Danguir and De SaintHilaire-Kafi, 1989) was reversed by SMS 201-995 or by octreotide, respectively.

The decrease of stage 4 sleep in our study resembles the decrease of NREMS after SRIF (Rezek et al, 1976) and after octreotide (Beranek et al, 1997, 1999) in the rat. Furthermore, wakefulness increased during the second half of the night. Similarly, sleep was impaired in healthy elderly subjects after repetitive i.v. SRIF (Frieboes et al, 1997). Since in young subjects sleep remained unchanged after SRIF (Parker et al, 1974; Kupfer et al, 1992; Steiger et al, 1992), we suggest that the longer half-life time of octreotide was the prerequisite to modulate sleep in young subjects in the present study. Interestingly, the administration of octreotide at 2245, relatively short before sleep onset, prompted a decrease of stage 4 sleep throughout the night in our study. Wakefulness increased only during the second half of the night. These observations point to a long-lasting effect of the substance on sleep-EEG. Our finding in humans is at variance with the increase of SWA, which followed the suppression of NREMS after octreotide in the rat (Beranek et al, 1997, 1999). The decrease of stage 4 sleep after octreotide is in contrast to the increase of SWS after GHRH in humans (Kerkhofs et al, 1993; Marshall et al, 1996; Steiger et al, 1992) and of NREMS in laboratory animals (Obál et al, 1988, 1996; Ehlers et al, 1986; Nistico et al, 1987; Obál and Krueger, 2001; Zhang et al, 1999) and after ghrelin in humans (Weikel et al, 2003) and in mice (Obál et al., 2003). We showed previously that the timing of GHRH administration is a crucial issue. Four hourly bolus injections between 2200 and 0100 induced an increase of SWS throughout the night in young men (Steiger et al, 1992). In contrast, i.v. GHRH between 0400 and 0700 did not promote sleep in young male subjects (Schier et al, 1997). It is thought that during an interval around sleep onset, endogenous GHRH exerts its sleep-promoting activity (Ehlers et al, 1986). We suggest that in the present study, octreotide inhibited GHRH activity during this crucial time window resulting in a deterioration of sleep throughout the night.

In a series of previous studies, we have shown specific effects of various peptides after repetitive i.v. administration on sleep-EEG in humans (Steiger and Holsboer, 1997). We argued that these changes represent the direct central effects of these peptides. From our present data, we also suggest that a single s.c. injection of octreotide is capable of exerting direct effects on CNS regulation. We suggest that SRIF participates in human sleep regulation as a sleep-impairing factor. GHRH and SRIF appear to exert opposite regulatory 
effects on pituitary GH release and, at least in male subjects, on sleep as well. A reciprocal interaction of GHRH and corticotropin-releasing hormone $(\mathrm{CRH})$ in the regulation of sleep-endocrine activity is well established (for review see Steiger, 2002). A synergism of SRIF and CRH in impairing sleep and enhancing vigilance appears likely. Besides, CRH SRIF may contribute to the changes of sleep-endocrine activity during depression and aging. The latter hypothesis is supported by our finding that the SRIF antagonist arginine enhances SWS in elderly subjects (Steiger et al, 2002). The role of peptides in sleep regulation in women needs further clarification since most studies in this field were performed in men and in male laboratory animals. A sexual dimorphism was observed in the sleep-endocrine effects of GHRH (Antonijevic et al, 2000a, b).

\section{ACKNOWLEDGEMENT}

This work was supported by a grant from the Deutsche Forschungsgemeinschaft (DFG 486/5-1).

\section{REFERENCES}

Antonijevic IA, Murck H, Frieboes RM, Barthelmes J, Steiger A (2000a). Sexually dimorphic effects of GHRH on sleep-endocrine activity in patients with depression and normal controls - Part I: the sleep EEG. Sleep Res Online 3: 5-13.

Antonijevic IA, Murck H, Frieboes RM, Steiger A (2000b). Sexually dimorphic effects of GHRH on sleep-endocrine activity in patients with depression and normal controls - Part II: hormone secretion. Sleep Res Online 3: 15-21.

Beranek L, Hajdu I, Gardi J, Taishi P, Obál Jr F, Krueger JM (1999). Central administration of the somatostatin analog octreotide induces captopril-insensitive sleep responses. Am J Physiol 277: R1297-R1304.

Beranek L, Obál Jr F, Taishi P, Bodosi B, Laczi F, Krueger JM (1997). Changes in rat sleep after single and repeated injections of the long-acting somatostatin analog octreotide. Am J Physiol 273: R1484-R1491.

Bracewell RN (1986). The Fast Hartley Transform. Oxford University Press: New York.

Bredow S, Taishi P, Obál Jr F, Guha-Thakurta N, Krueger JM (1996). Hypothalamic growth hormone-releasing hormone mRNA varies across the day in rat. NeuroReport 7: 2501-2505.

Danguir J (1986). Intracerebroventricular infusion of somatostatin selectively increases paradoxical sleep in rats. Brain Res 367: 26-30.

Danguir J (1989). The somatostatin analogue SMS 201-995 promotes paradoxical sleep in aged rats. Neurobiol Aging 10: 367-369.

Danguir J, De Saint-Hilaire-Kafi S (1988). Scopolamine-induced suppression of paradoxical sleep is reversed by the somatostatin analogue SMS 201-995 in rats. Pharmacol Biochem Behav 30: 295-297.

Danguir J, De Saint-Hilaire-Kafi S (1989). Reversal of desipramineinduced suppression of paradoxical sleep by a long-acting somatostatin analogue (octreotide) in rats. Neurosci Lett 98: 154-158.

Ehlers CL, Reed TK, Henriksen SJ (1986). Effects of corticotropinreleasing factor and growth hormone-releasing factor on sleep and activity in rats. Neuroendocrinology 42: 467-474.

Frieboes RM, Murck H, Schier T, Holsboer F, Steiger A (1997). Somatostatin impairs sleep in elderly human subjects. Neuropsychopharmacology 16: 339-345.
Gardi J, Obál Jr F, Fang J, Zhang J, Krueger JM (1999). Diurnal variations and sleep deprivation-induced changes in rat hypothalamic GHRH and somatostatin contents. Am J Physiol 277: R1339-R1344.

Gardi J, Szentirmai E, Hajdu I, Obál Jr F, Krueger JM (2001). The somatostatin analogue octreotide causes accumulation of growth hormone-releasing hormone and depletion of angiotensin in the rat hypothalamus. Neurosci Lett 315: 37-40.

Guldner J, Schier T, Friess E, Colla M, Holsboer F, Steiger A (1997). Reduced efficacy of growth hormone-releasing hormone in modulating sleep endocrine activity in the elderly. Neurobiol Aging 18: 491-495.

Hajdu I, Obál Jr F, Fang J, Krueger JM, Rollo CD (2002). Sleep of transgenic mice producing excess rat growth hormone. Am J Physiol Regul Integr Comp Physiol 282: R70-R76.

Holsboer F, von Bardeleben U, Steiger A (1988). Effects of intravenous corticotropin-releasing hormone upon sleep-related growth hormone surge and sleep EEG in man. Neuroendocrino$\log y$ 48: 32-38.

Kerkhofs M, Van Cauter E, Van Onderbergen A, Caufriez A, Thorner MO, Copinschi G (1993). Sleep-promoting effects of growth hormone-releasing hormone in normal men. Am J Physiol 264: E594-E598.

Kojima M, Hosoda H, Date Y, Nakazato M, Matsuo H, Kangawa K (1999). Ghrelin is a growth hormone-releasing acylated peptide from stomach. Nature 402: 656-660.

Kupfer DJ, Jarrett DB, Ehlers CL (1992). The effect of SRIF on the EEG sleep of normal men. Psychoneuroendocrinology 17: 37-43.

Lancel M, Steiger A (1999). Sleep and its modulation by drugs that affect GABA(A) receptor function. Angew Chem Int Ed 38: 2853-2864.

Lauer C, Riemann D, Wiegand M, Berger M (1991). From early to late adulthood. Changes in EEG sleep of depressed patients and healthy volunteers. Biol Psychiatry 29: 979-993.

Marshall L, Mölle M, Böschen G, Steiger A, Fehm HL, Born J (1996). Greater efficacy of episodic than continuous growth hormone releasing hormone (GHRH) administration in promoting slow wave sleep (SWS). J Clin Endocrinol Metab 81: 1009-1013.

Murck H, Guldner J, Colla-Müller M, Frieboes RM, Schier T, Wiedemann K et al (1996). VIP decelerates non-REM-REM cycles and modulates hormone secretion during sleep in men. Am J Physiol 271: R905-R911.

Nistico G, De Sarro GB, Bagetta G, Muller EE (1987). Behavioural and electrocortical spectrum power effects of growth hormone releasing factor in rats. Neuropharmacology 26: 75-78.

Obál Jr F, Alföldi P, Cady AB, Johannsen L, Sary G, Krueger JM (1988). Growth hormone-releasing factor enhances sleep in rats and rabbits. Am J Physiol 255: R310-R316.

Obál Jr F, Alt J, Taishi P, Gardi J, Krueger JM (2003). Sleep in mice with non-functional growth hormone releasing hormone receptors. Am J Physiol 284: R131-R139.

Obál Jr F, Fang J, Taishi P, Kacsóh B, Gardi J, Krueger JM (2001). Deficiency of growth hormone-releasing hormone signaling is associated with sleep alterations in the dwarf rat. J Neurosci 21: 2912-2918.

Obál Jr F, Floyd R, Kapás L, Bodosi B, Krueger JM (1996). Effects of systemic GHRH on sleep in intact and in hypophysectomized rats. Am J Physiol 270: E230-E237.

Obál Jr F, Krueger JM (2001). The somatotrophic axis and sleep. Rev Neurol (Paris) 157: 5S12-5S15.

Obál Jr F, Krueger JM (2002). Biochemical regulation of nonrapid-eye-movement sleep. Front Biosci 8: s520-s550.

Obál Jr F, Payne L, Kapás L, Opp M, Krueger JM (1991). Inhibition of growth hormone-releasing factor suppresses both sleep and growth hormone secretion in the rat. Brain Res 557: 149-153. 
Obál Jr F, Payne L, Opp M, Alföldi P, Kapás L, Krueger JM (1992). Growth hormone-releasing hormone antibodies suppress sleep and prevent enhancement of sleep after sleep deprivation. $A m J$ Physiol 263: R1078-R1085.

Parker DC, Rossman LG, Siler TM, Rivier J, Yen SS, Guillemin R (1974). Inhibition of the sleep-related peak in physiologic human growth hormone release by somatostatin. J Clin Endocr Metab 38: 496-499.

Rechtschaffen A, Kales A (1968). A Manual of Standardized Terminology, Techniques and Scoring System for Sleep Stages of Human Subjects US Department of Health, Education \& Welfare, Neurological Information Network, Bethesda, MD, USA.

Reisine T (1995). Somatostatin receptors. Am J Physiol 269: G813-G820.

Rezek M, Havlicek V, Hughes KR, Friesen H (1976). Cortical administration of somatostatin (SRIF): effect on sleep and motor behavior. Pharmacol Biochem Behav 5: 73-77.

Schier T, Guldner J, Colla M, Holsboer F, Steiger A (1997). Changes in sleep-endocrine activity after growth hormone-releasing hormone depend on time of administration. J Neuroendocrinol 9: 201-205.

Steiger A (2002). Sleep and endocrine regulation. Frontiers Biosci 8: $358-376$.

Steiger A, Guldner J, Hemmeter U, Rothe B, Wiedemann K, Holsboer F (1992). Effects of growth hormone-releasing hormone and somatostatin on sleep EEG and nocturnal hormone secretion in male controls. Neuroendocrinology 56: 566-573.

Steiger A, Holsboer F (1997). Neuropeptides and human sleep. Sleep 20: 1038-1052.

Steiger A, Trachsel L, Guldner J, Hemmeter U, Rothe B, Rupprecht $\mathrm{R}$ et al (1993). Neurosteroid pregnenolone induces sleep-EEG changes in man compatible with inverse agonistic $\mathrm{GABA}_{\mathrm{A}^{-}}$ receptor modulation. Brain Res 615: 267-274.

Steiger A, Weikel J, Held K, Schmid D, Ziegenbein M (2002). Arginine improves sleep in elderly men. Sleep 25: A203.

Trachsel L, Edgar DM, Seidel WF, Heller HC, Dement WC (1992). Sleep homeostasis in suprachiasmatic nuclei-lesioned rats: effects of sleep deprivation triazolam administration. Brain Res 589: 253-261.

Weikel JC, Wichniak A, Ising M, Brunner H, Friess E, Held K et al (2003). Ghrelin promotes slow-wave sleep in man. Am J Physiol Endocrinol Metab 284: E407-E415.

Williams RL, Karacan I, Hursch CJ (1974). Electroencephalography (EEG) of Human Sleep: Clinical Applications. Wiley: New York.

Zhang J, Obál Jr F, Fang J, Collins BJ, Krueger JM (1996). Non-rapid eye movement sleep is suppressed in transgenic mice with a deficiency in the somatotrophic system. Neurosci Lett 220: 97-100.

Zhang J, Obál Jr F, Zheng T, Fang J, Taishi P, Krueger JM (1999). Intrapreoptic microinjection of GHRH or its antagonist alters sleep in rats. J Neurosci 19: 2187-2194. 